\title{
Facts for Life and Helicobacter Pylori Infection
}

\author{
Umut Eren Erdoğdu1 ${ }^{1}$, (D) Hakan Demirci ${ }^{2}$, () Hacı Murat Çaycı ${ }^{1}$, (i) Taşkın Erkinüresin ${ }^{3}$ \\ ${ }^{1}$ Department of General Surgery, University of Health Sciences Bursa Yuksek Ihtisas Training and Research Hospital, Bursa, Turkey \\ ${ }^{2}$ Department of Family Medicine, University of Health Sciences Bursa Yuksek Ihtisas Training and Research Hospital, Bursa, Turkey \\ ${ }^{3}$ Department of Pathology, University of Health Sciences Bursa Yuksek Ihtisas Training and Research Hospital, Bursa, Turkey
}

\begin{abstract}
Introduction: Helicobacter pylori (HP) disease is associated with poor hygiene. Similarly, poor health literacy (HL) is also associated with poor hygienic conditions. The present study aims to investigate the relationship between HL and HP disease, two conditions associated with poor hygiene.

Methods: The data from 326 patients who applied to the general surgery clinic with dyspepsia and underwent gastroscopy were evaluated in cross-sectional analytical design. Esophagus, stomach and duodenum were evaluated, and biopsy of the antrummucosa was performed in these patients. According to report results, patients were divided into two groups as HP (+) and HP (-). Public Health Literacy Scale consisting of the questions of 'Facts of Life' was applied to the patients to evaluate their $\mathrm{HL}$.

Results: The findings showed that there was no relationship between the presence of HP infection and HL. In individuals with higher $\mathrm{HL}$, consumption of clean water, increased use of pasteurized milk and toilet hygiene were observed. A positive correlation was found between the increase in $\mathrm{HL}$ scores and the search for HP eradication therapy.

Discussion and Conclusion: Better HL is associated with hygienic behavior and help-seeking behavior for the treatment of HP. Efforts to increase HL in people with HP infection will positively affect the treatment of these patients.

Keywords: Facts for life; gastroscopy; health literacy; helicobacter pylori; hygiene.
\end{abstract}

$\mathrm{H}$ elicobacter pylori (HP) is a microaerophilic, gram-negative microorganism. HP gastritis is an infectious disease that is transmitted through the oral-oral, fecal-oral and gastro-oral route ${ }^{[1]}$. There is a high prevalence of HP infection in countries with low socioeconomic status and poor sanitary conditions, and the prevalence of HP infection is remarkably lower in the Northern and Western European countries than in the Southern and Eastern European countrie $^{[2]}$.

HP positivity in gastric biopsy samples has been linked previously to various factors in the literature ${ }^{[3]}$, with the most extensively studied factors being the consumption of clean water, the consumption of pasteurized milk, chronic antibiotic use and transmission during previous endoscopic examinations. Similarly, the presence of hypertension, high carbohydrate consumption and obesity are among the patient-specific factors that have been implicated ${ }^{[4-6]}$.

Health Literacy $(\mathrm{HL})$ was defined as the cognitive and social skills that determine the motivation and ability of individuals to gain access to, understand and use information in ways that promote and maintain good health ${ }^{[7]}$. The clinical approach to health literacy developed in the

Correspondence (İletişim): Hakan Demirci, M.D. Saglik Bilimleri Universitesi Bursa Yuksek Ihtisas Egitim ve Arastirma Hastanesi, Aile Hekimligi Anabilim Dali, Bursa, Turkey

Phone (Telefon): +90 5368963330 E-mail (E-posta): drhakandemirci@hotmail.com

Submitted Date (Başvuru Tarihi): 27.04.2019 Accepted Date (Kabul Tarihi): 13.05.2019

Copyright 2020 Haydarpaşa Numune Medical Journal

OPEN ACCESS This is an open access article under the CC BY-NC license (http://creativecommons.org/licenses/by-nc/4.0/) 
United States aims to improve the understanding of the disease and treatment regimens of the patients by doctors, and the understanding of the doctor's prescription by the patients ${ }^{[8]}$. Patients with a higher $\mathrm{HL}$ have easier access to healthcare services, and similarly, have a higher rate of access to protective healthcare services. In addition, individuals with high $\mathrm{HL}$ have been more successful in improving their health status. Health literacy is considered to be equivalent to good health status ${ }^{[8]}$.

'Facts for Life' is a joint publication of UNICEF, WHO, UNESCO, UNFPA, UNDP, WFP, UNAIDS and the World Bank. 'Facts for Life' aims to provide families and communities with the information they need to save and improve children's lives. Pleasant et al. ${ }^{[9]}$ developed the "Public Health Literacy" scale, which contains 17 items compiled from knowledge garnered from the "Facts for Life". This scale measures the general health knowledge of the individual. While the original "Facts for life" targets children's health and diseases, Pleasant et al. developed a scale for the general evaluation of health literacy in their study, containing questions assessing knowledge of communicable diseases, children's health, contraception and general health.

Previous studies have found HP to be related to poor hygiene in general terms ${ }^{[10-12]}$. The present study evaluates the relationship between $\mathrm{HL}$ and $\mathrm{HP}$ infection.

\section{Materials and Methods}

\section{Study Design}

The data of 326 patients who presented to the general surgery outpatient clinics of the Bursa Higher Specialization Training and Research Hospital of the University of Health Sciences with dyspeptic complaints between May 2018 and August 2018, and who underwent a gastroscopy, were evaluated in a cross-sectional study design. Detailed information about the study was provided to the patients before the study, and written informed consent for participation was obtained. This study was conducted in accordance with the principles of the Helsinki Declaration, and the local ethics committee of the hospital approved this study.

\section{Participants}

Included in this study were literate patients aged 18 years and older. Patients who did not give their consent to participate in the survey, patients who were illiterate and healthcare personnel were excluded from this study. The demographic data of the patients were recorded. The patients were divided into two groups as HP-positive $(\mathrm{HP}+, \mathrm{n}=154)$ and HP-negative (HP-, $\mathrm{n}=172$ ).

\section{Interventions}

After arranging an appointment with the endoscopy unit for patients presenting to the general surgery outpatient clinics with dyspeptic complaints, a gastroscopy was performed by the same surgical team under oral local anesthesia following eight hours of fasting. The esophagus, stomach and duodenum were examined, and biopsies were obtained from the antral mucosa. The specimens were fixed in a formalin solution and sent to the pathology laboratory. The patients were divided into groups according to the results of the analysis as $\mathrm{HP}$-positive $(\mathrm{HP}+)$ and HP-negative (HP-).

The public health literacy questionnaire was administered to the volunteers containing items based on the questions in "Facts for Life" and on expert opinion. The scale is a 17item instrument in which questions are responded to as either correct or incorrect ${ }^{[9]}$. No validation of the Turkish version of the scale was sought because the items in the scale are widely known internationally, as reported by WHO.

\section{Statistical Analysis}

A Shapiro Wilk test was used to test for the normal distribution of the variables. Continuous variables were expressed as median (minimum: maximum); categorical variables were expressed as number and percentage. A Mann-Whitney U-test was used to compare the two groups based on the results of the normality test, and a Kruskal Wallis was used to compare three groups. A Pearson's Chi-square test, Fisher's exact test and Fisher-Freeman-Halton test were used for the intergroup comparison of the categorical variables. The SPSS (IBM Corp. Released 2012. IBM SPSS Statistics for Windows, Version 21.0. Armonk, NY: IBM Corp.) Software package was used in the statistical analysis and a $p$-value of $<0.05$ was considered statistically significant.

\section{Results}

Included in this study were 326 patients, 206 of them were female, and 120 were male. The distribution of the sociodemographic variables of the participants is presented in Table 1. The median age was 45 years in the HP+ group and 49 years in the HP- group, and there was a significant difference between the two groups ( $p=0.047$ ). No difference was found between the groups concerning gender, height, weight, $\mathrm{BMI}$, education level, occupation and marital status (Table 1). The factors that might affect HP positivity are examined in Table 2. The two groups were compared concerning smoking status, alcohol consumption, type of water consumed (tap vs. bottled), milk consumption (loose milk vs. pasteur- 
Table 1. Comparison of the sociodemographic characteristics between the HP groups

\begin{tabular}{|c|c|c|c|}
\hline & HP (+) & HP (-) & $\mathbf{p}$ \\
\hline Age & 45 (19: 86) & 49 (18: 84) & $0.047^{\mathrm{a}}$ \\
\hline \multicolumn{4}{|l|}{ Gender, (\%) } \\
\hline Male & $52(33.80)$ & $68(39.50)$ & $0.281^{\mathrm{b}}$ \\
\hline Female & $102(66.20)$ & $104(60.50)$ & \\
\hline Height (cm) & $165(140: 194)$ & $165(140: 193)$ & $0.591^{\mathrm{a}}$ \\
\hline Weight (kg) & 75 (43:152) & 75 (45:195) & $0.589^{a}$ \\
\hline BMI & $27.70(17.90: 47)$ & $27.50(17.60: 67.50)$ & $0.740^{\mathrm{a}}$ \\
\hline \multicolumn{4}{|l|}{ Education, (\%) } \\
\hline Illiterate & $16(10.40)$ & $21(12.20)$ & $0.594^{b}$ \\
\hline Literate & $11(7.10)$ & $6(3.50)$ & \\
\hline Primary school & $52(33.80)$ & $64(37.20)$ & \\
\hline Secondary School & $28(18.20)$ & $24(14)$ & \\
\hline High school & $29(18.80)$ & $37(21.50)$ & \\
\hline Associate degree & $8(5.20)$ & $8(4.70)$ & \\
\hline Undergraduate & $9(5.80)$ & $8(4.70)$ & \\
\hline Postgraduate & $1(0.60)$ & $4(2.30)$ & \\
\hline \multicolumn{4}{|l|}{ Occupation, (\%) } \\
\hline Present & $62(40.30)$ & $66(38.40)$ & $0.728^{b}$ \\
\hline Absent & $92(59.70)$ & $106(61.60)$ & \\
\hline \multicolumn{4}{|l|}{ Level of Income, (\%) } \\
\hline Very low & $2(1.30)$ & $3(1.70)$ & $0.785^{c}$ \\
\hline Low & $8(5.20)$ & $10(5.80)$ & \\
\hline Moderate & $115(74.70)$ & $130(75.60)$ & \\
\hline High & $29(18.80)$ & $27(15.70)$ & \\
\hline Very high & 0 & $2(1.20)$ & \\
\hline \multicolumn{4}{|l|}{ Marital status, (\%) } \\
\hline Single & $23(14.90)$ & $26(15.10)$ & $0.416^{b}$ \\
\hline Married & $126(81.80)$ & $135(78.50)$ & \\
\hline Divorced & $5(3.20)$ & $11(6.40)$ & \\
\hline
\end{tabular}

The data are presented as median (minimum: maximum) and

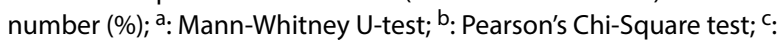
Fisher-Freeman-Halton Test.

ized milk), use of bathroom tissue, history of gastroscopy, $\mathrm{HP}$ eradication status and antibiotic use in the last one year. No statistically significant difference was found between the groups in these parameters.

In the analysis of responses to the questions from "Facts for Life" (Table 3), the health literacy (HL) score was 12 points in patients consuming tap water and 13 points in patients consuming bottled water, and the difference between the groups was statistically significant $(p=0.002)$. The HL score was 13 points in patients using bathroom tissue and 12 points in patients who did not use, and the difference was found to be statistically significant ( $p=0.018$ ). The score of the patients who underwent HP eradication therapy was 14 points, whereas the score of the patients who did not
Table 2. Comparison of the factors that could affect helicobacter pylori positivity

\begin{tabular}{|c|c|c|c|}
\hline & HP (+) & HP (-) & $\mathbf{p}$ \\
\hline \multicolumn{4}{|l|}{ Smoking, (\%) } \\
\hline Present & $40(26)$ & $45(26.20)$ & $0.969^{b}$ \\
\hline Absent & $114(74)$ & $127(73.80)$ & \\
\hline \multicolumn{4}{|l|}{ Alcohol, (\%) } \\
\hline Present & $2(1.30)$ & $2(1.20)$ & $1.000^{d}$ \\
\hline Absent & $152(98.70)$ & $170(98.80)$ & \\
\hline \multicolumn{4}{|c|}{ Water Consumption, (\%) } \\
\hline Tap & $92(59.70)$ & $92(53.50)$ & $0.256^{b}$ \\
\hline Bottled & $62(40.30)$ & $80(46.50)$ & \\
\hline \multicolumn{4}{|c|}{ Milk Consumption, (\%) } \\
\hline Loose & $87(56.50)$ & $103(59.90)$ & $0.535^{d}$ \\
\hline Pasteurized & $67(43.50)$ & $69(40.10)$ & \\
\hline \multicolumn{4}{|c|}{ Use of bathroom tissue, (\%) } \\
\hline Yes & $142(92.20)$ & $148(86)$ & $0.076^{\mathrm{b}}$ \\
\hline No & $12(7.80)$ & $24(14)$ & \\
\hline \multicolumn{4}{|c|}{ History of Gastroscopy, (\%) } \\
\hline No & $101(65.60)$ & $98(57)$ & $0.281^{a}$ \\
\hline State hospital & $42(27.30)$ & $59(34.30)$ & \\
\hline Private hospital & $11(7.10)$ & $15(8.70)$ & \\
\hline \multicolumn{4}{|c|}{ HP eradication therapy, (\%) } \\
\hline Yes & $10(6.50)$ & $17(9.90)$ & $0.268^{b}$ \\
\hline No & $144(93.50)$ & 155 (90.10) & \\
\hline \multicolumn{4}{|l|}{ Antibiotic use in the } \\
\hline \multicolumn{4}{|l|}{ last one year, (\%) } \\
\hline Yes & $94(61)$ & $113(65.70)$ & $0.383^{d}$ \\
\hline No & $60(39)$ & $59(34.10)$ & \\
\hline
\end{tabular}

The data are expressed as n (\%); b: Pearson's Chi-Square test; $d$ : Fisher's Exact Test.

receive such therapy was 12 points, and the difference was statistically significant $(p=0.024)$. The $\mathrm{HL}$ score was 13 points in patients who had used antibiotics in the last one year and 12 points in patients who had not, showing a significant difference between the groups ( $p=0.002$ ).

The HL scores of the groups did not differ significantly concerning HP status, smoking status, alcohol consumption, milk consumption and history of gastroscopy (Table 3 ).

\section{Discussion}

In the present study sample, subjects with a high HL score exhibited more hygienic behaviors. An increase was noted in clean water consumption, pasteurized milk consumption, and use of bathroom tissue as HL increased. The pursuit of HP eradication therapy was remarkable in increasing health literacy.

Helicobacter pylori are found in the environment, although 
Table 3. Comparison of the HL scores

\begin{tabular}{|c|c|c|c|}
\hline & $\mathbf{n}$ & Health literacy score & $\mathbf{p}$ \\
\hline \multicolumn{4}{|l|}{ Helicobacter pylori } \\
\hline Positive & 154 & $13(3: 23)$ & $0.516^{a}$ \\
\hline Negative & 172 & $13(4: 17)$ & \\
\hline \multicolumn{4}{|l|}{ Smoking } \\
\hline Yes & 85 & $13(4: 23)$ & $0.237^{a}$ \\
\hline No & 241 & $12(3: 17)$ & \\
\hline \multicolumn{4}{|l|}{ Alcohol } \\
\hline Yes & 4 & $12.50(10: 14)$ & $0.765^{a}$ \\
\hline No & 322 & $13(3: 23)$ & \\
\hline \multicolumn{4}{|l|}{ Water consumption } \\
\hline Tap & 184 & $12(5: 17)$ & $0.002^{a}$ \\
\hline Bottled & 142 & $13(3: 23)$ & \\
\hline \multicolumn{4}{|l|}{ Milk Consumption } \\
\hline Loose & 190 & $12(5: 17)$ & $0.431^{\mathrm{a}}$ \\
\hline Pasteurized & 136 & $13(3: 23)$ & \\
\hline \multicolumn{4}{|c|}{ Use of bathroom tissue } \\
\hline Yes & 290 & $13(3: 23)$ & $0.018^{\mathrm{a}}$ \\
\hline No & 36 & $12(6: 17)$ & \\
\hline \multicolumn{4}{|c|}{ History of Gastroscopy } \\
\hline No & 199 & $12(3: 17)$ & $0.320^{e}$ \\
\hline State hospital & 101 & $13(4: 23)$ & \\
\hline Private hospital & 26 & $13(9: 16)$ & \\
\hline \multicolumn{4}{|c|}{ HP eradication therapy } \\
\hline Yes & 27 & $14(9: 23)$ & $0.024^{a}$ \\
\hline No & 299 & $12(3: 17)$ & \\
\hline \multirow{2}{*}{\multicolumn{4}{|c|}{$\begin{array}{l}\text { Antibiotic use in the } \\
\text { last one year }\end{array}$}} \\
\hline & & & \\
\hline Yes & 207 & $13(4: 23)$ & $0.002^{a}$ \\
\hline No & 119 & $12(3: 17)$ & \\
\hline
\end{tabular}

The data are presented as median (minimum: maximum); a: Mann-Whitney U-test, ${ }^{e}$ : Kruskal Wallis test.

in which segment of the population, this agent will cause an established disease in the gastric mucosa is yet to be understood $^{[13]}$. Various etiological causes reported in the literature, such as smoking, obesity, history of HP eradication therapy and history of gastroscopy, which have been found not to be associated with HP positivity ${ }^{[3]}$. The present study is based on histopathological examination results, which are the gold standard for HP detection. In the study sample, HP positivity was probably affected by causes other than the causes investigated in the present study. The identification of this microorganism and the treatment of infected individuals are important public health problems given that the microorganism plays a role in the etiopathogenesis of peptic ulcus and gastric cancer. Further studies of this disease are required, which unfortunately has a high prevalence in this geographic region.

The association between health literacy and hygienic behaviors is an expected finding ${ }^{[10-12]}$. The Public Health Literacy scale is a knowledge scale that assesses the health knowledge of individuals, and the tendency of individuals with knowledge of healthy living to engage in hygienic behaviors is a reflection of their endeavors to make use of this knowledge. Pasteurized milk is safer than loose milk, and studies have revealed that bottled water is safer than tap water ${ }^{[14]}$. Although the cleanliness of town water has been demonstrated through water analyses, it is a common notion that bottled water is much cleaner. In addition, studies have also demonstrated the importance of using bathroom tissue for personal hygiene ${ }^{[15]}$. Volunteers with higher health literacy scores were more careful in this regard. HP is widely found in the environment and ingested by humans, although the bacteria do not cause infection in all individuals ${ }^{[13]}$. It has been noted, however, that hygienic behaviors fail to prevent HP infection.

The three main components of health literacy are disease prevention, improvement of health and access to healthcare services ${ }^{[16]}$. The present study found a relationship between access to healthcare services and health literacy. Similarly, previous studies have found that individuals with a higher health literacy score experienced greater success in the treatment of chronic diseases ${ }^{[17,18]}$. For example, a decrease in $\mathrm{HbA} 1 \mathrm{c}$ levels was noted with increasing health literacy in patients with diabetes mellitus ${ }^{[19]}$. The mean doses of drugs inhaled in patients with chronic obstructive pulmonary disease increase as health literacy decreases ${ }^{[20]}$. The rate of accessing bariatric surgery as the mean of definitive therapy increases with increasing health literacy in the morbidly obese ${ }^{[21]}$. These examples can be extended further, and the present study identifies an association between health literacy and seeking eradication therapy in patients with HP infection.

\section{Limitations}

This study has various limitations, one of which is its single-center study design, which prevents the results of the present study from being generalized. In addition, the use of a validated scale would be better, although the "Facts for Life" were considered to be sufficiently internationally known, and so no validation was sought ${ }^{[22]}$.

\section{Conclusion}

In conclusion, health literacy was found to be associated with the pursuit of therapy in the respondents with HP in- 
fection. Health literacy is associated with hygienic behavior, although such behaviors were not found to be associated with HP positivity. Although the individuals exhibit hygienic behaviors, other causes can be suggested as influential in the occurrence of the disease.

Ethics Committee Approval: The Ethics Committee of Bursa Yüksek Ihtisas Training and Research Hospital provided the ethics committee approval for this study (2011-KAEK-25 2018/06-02/20).

Peer-review: Externally peer-reviewed.

Authorship Contributions: Concept: U.E.E.; Design: U.E.E., H.D.; Data Collection or Processing: H.M.Ç., T.E.; Analysis or Interpretation: U.E.E., H.D.; Literature Search: H.M.Ç., T.E.; Writing: U.E.E., H.D.

Conflict of Interest: None declared.

Financial Disclosure: The authors declared that this study received no financial support.

\section{References}

1. Sugano K, Tack J, Kuipers EJ, Graham DY, El-Omar EM, Miura S, et al; faculty members of Kyoto Global Consensus Conference. Kyoto global consensus report on Helicobacter pylori gastritis. Gut 2015;64:1353-67. [CrossRef]

2. Roberts SE, Morrison-Rees S, Samuel DG, Thorne K, Akbari A, Williams JG. Review article: the prevalence of Helicobacter pylori and the incidence of gastric cancer across Europe. Aliment Pharmacol Ther 2016;43:334-45. [CrossRef]

3. Brown LM. Helicobacter pylori: epidemiology and routes of transmission. Epidemiol Rev 2000;22:283-97. [CrossRef]

4. Siddiqui B, Yakoob J, Abbas Z, Azmat R, Fatima SS, Awan S. Distribution of Helicobacter pylori infection and abnormal body-mass index (BMI) in a developing country. The Journal of Infection in Developing Countries 2018;12:342-6. [CrossRef]

5. Kountouras J, Polyzos SA, Doulberis M, Zeglinas C, Artemaki F, Vardaka E, et al. Potential impact of Helicobacter pylori-related metabolic syndrome on upper and lower gastrointestinal tract oncogenesis. Metabolism 2018;87:18-24. [CrossRef]

6. Kim YI, Kim YA, Lee JW, Kim HJ, Kim SH, Kim SG, et al. Effect of Helicobacter pylori Treatment on Long-Term Mortality in Patients with Hypertension. Gut Liver 2019. [CrossRef]

7. Nutbeam D. Health literacy as a public health goal: a challenge for contemporary health education and communication strategies into the 21st century. Health Promotion International 2000;15:259-67. [CrossRef]

8. Turkoglu AR, Demirci H, Coban S, Guzelsoy M, Toprak E, Aydos $M M$, et al. Evaluation of the relationship between compliance with the follow-up and treatment protocol and health literacy in bladder tumor patients. Aging Male 2019;22:266-271.

9. Pleasant A, Kuruvilla S. A tale of two health literacies: public health and clinical approaches to health literacy. Health Promot Int 2008;23:152-9. [CrossRef]

10. van Duynhoven YT, de Jonge R. Transmission of Helicobacter pylori: a role for food? Bull World Health Organ 2001;79:45560.

11. Anand PS, Nandakumar K, Shenoy KT. Are dental plaque, poor oral hygiene, and periodontal disease associated with Helicobacter pylori infection? J Periodontol 2006;77:692-8. [CrossRef]

12. Perez-Perez Gl, Rothenbacher D, Brenner H. Epidemiology of Helicobacter pylori infection. Helicobacter 2004;9:1-6. [CrossRef]

13. Blaser MJ. Intrastrain differences in Helicobacter pylori: a key question in mucosal damage? Annals of Medicine 1995;27:559-63. [CrossRef]

14. Ozaydin N, Turkyilmaz SA, Cali S. Prevalence and risk factors of helicobacter pylori in Turkey: a nationally-representative, cross-sectional, screening with the $13 \mathrm{C}$-Urea breath test. BMC Public Health 2013;13:1215. [CrossRef]

15. Michaels B, Gangar V, Schattenberg H, Blevins M, Ayers T. Effectiveness of cleaning methodologies used for removal of physical, chemical and microbiological residues from produce. Food Service Technology 2003;3:9-15. [CrossRef]

16. Sørensen K, Van den Broucke S, Fullam J, Doyle G, Pelikan J, Slonska Z, et al. Health literacy and public health: a systematic review and integration of definitions and models. BMC Public Health 2012;12:80. [CrossRef]

17. Bozkurt H, Demirci $H$. Health literacy among older persons in Turkey. Aging Male 2019;22:272-7. [CrossRef]

18. Esen İ, Demirci H, Güçlü M, Esen SA, Şimşek EE. The Relationship Between Health Literacy, Diabetic Control, and Disease-Specific Complications in Patients with Type 1 Diabetes Mellitus. South Clin Ist Euras 2018;29:151-6. [CrossRef]

19. Heisler M, Piette JD, Spencer M, Kieffer E, Vijan S. The relationship between knowledge of recent $\mathrm{HbA} 1 \mathrm{c}$ values and diabetes care understanding and self-management. Diabetes Care 2005;28:816-22. [CrossRef]

20. Ture DA, Demirci $H$, Sengoren Dikis O. The relationship between health literacy and disease specific costs in subjects with chronic obstructive pulmonary disease (COPD). Aging Male 2018:1-7. [CrossRef]

21. Cayci HM, Erdogdu UE, Demirci H, Ardic A, Topak NY, Taymur i. Effect of health literacy on help-seeking behavior in morbidly obese patients agreeing to bariatric surgery. Obes Surg 2018;28:791-7. [CrossRef]

22. Alper Z, Ozdemir H, Bilgel N. The knowledge of "Facts for Life". Educ Health (Abingdon) 2005;18:209-23. [CrossRef] 